\title{
Prevalence of Herpes Simplex Virus Type 1 and 2 Infections in Renal Transplant Recipients and Their Renal Function
}

\author{
Ali Farhadi ${ }^{* 1}{ }^{(\mathbb{D})}$, Abbas Behzad Behbahani $^{(\mathbb{1})}, \operatorname{Ramin}$ Yaghobi $^{(\mathbb{1})}$, Mehdi Salehipour $^{4}$ \\ 1. Assistant professor of Medical Virology, Department of Medical Laboratory Sciences, School of Para- \\ medical Sciences, Shiraz University of Medical Sciences, Shiraz, Iran. \\ 2. Professor of Medical Virology, Diagnosis Laboratory Sciences and Technology Research Center, Shiraz \\ University of Medical Sciences, Shiraz, Iran. \\ 3. Associate professor of Medical Virology, Transplant Research Center, Shiraz University of Medical Sci- \\ ences, Shiraz, Iran. \\ 4. Associate professor of Urology, Department of urology, Shiraz university medical sciences, Shiraz, Iran
}

\section{Article Information}

Article History

Received: $\quad 2019 / 11 / 25$

Accepted: $\quad 2020 / 05 / 07$

Available Online: 2020/05/24

JUR 2019; 3(2):41-48

DOI: $10.30699 / j r u .3 .2 .40$

Use your device to scan and read the article online

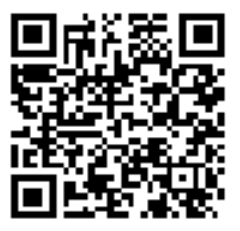

Corresponding Author

Ali Farhadi

Associate professor of Urology, Department of urology, Shiraz university medical sciences, Shiraz, Iran

Tel: $071-32270301$

Email:

farhadi_a@sums.ac.ir

\section{Abstract}

Background \& Objective: Viral infections are a major problem for transplant recipients. Reactivation of viruses is associated with the use of strong immunosuppressive drugs. Herpes simplex virus infections in renal transplant patients may become severe without treatment. Although the prevalence and role of herpes simplex viruses 1 and 2 in bone marrow and lung recipients are well known; however, the prevalence of the virus from the time of transplantation to the one-year period after transplantation is vague. The aim of this study was to investigate the prevalence of herpes simplex virus infections and renal function after transplantation.

Methods: In a prospective single-center study we followed 58 renal transplant recipients who received a living or cadaveric kidney transplant at Namazi hospital. Samples were taken from each individual 1 week before transplantation and 2 weeks post-transplantation. The patients were then sampled every 4 weeks up to 52 weeks after transplantation. Urine and blood samples were also collected from 37 organ donors. We investigated the presence of HSV-DNA in the urine and peripheral blood samples of renal transplant recipients using PCR-RFLP. The presence of viral DNA in the urine and peripheral blood samples of living donors were investigated as well. The patients were also examined for any signs or symptoms of renal dysfunction.

Results: HSV-1 DNA was detected in urine samples of only $19 \%$ of transplant patients. HSV-2 DNA, however, was not detected in any group of subjects including renal transplant recipients. A significant association was observed between HSV-1 infection among kidney recipients and donors $(P=0.002)$.

Conclusions: Although there was no significant association between HSV-1 infection and renal dysfunction in renal transplant recipients, however, due to life-threatening infections caused by this virus, periodic testing for the presence of HSV-1 is recommended.

Keywords: HSV 1 and 2, Renal Transplant Recipients, PCR-RFLP

How to cite this article:

Farhadi A, Behzad Behbahani A, Yaghobi R, Salehipour M. Prevalence of herpes simplex virus type 1 and 2 infections in renal transplant recipients and their renal function. J Res Urol. 2019; 3 (2) : 


\section{مقاله هُونش}

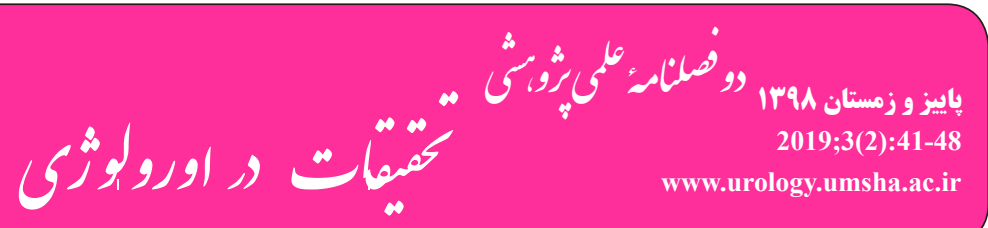

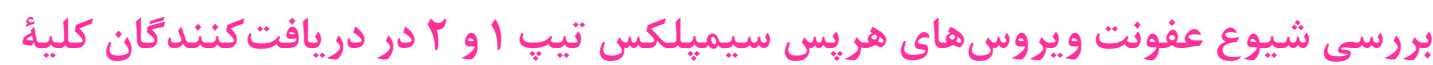
ييوندى و ميزان عملكرد كليوى آنان

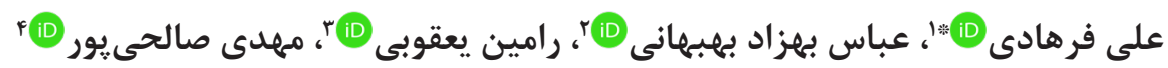

ا. استاديار، كروه علومآزمايشكاهى، دانشكده يِيرايزشكى، دانشكاه علوميزشكى شيراز، ايران

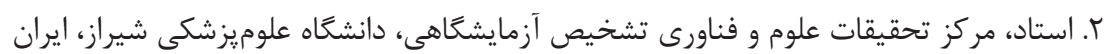

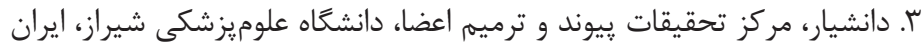

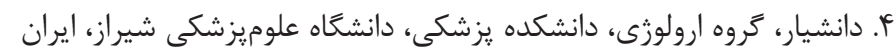

جكيده

زمينه و هدف: در بيمارانى كه عمل يِيوند عضو انجام دادهاند، به دليل استفاده از داروهاى سر كوبكنندة

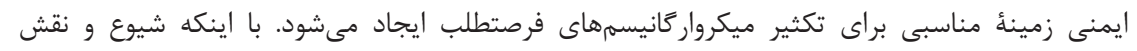

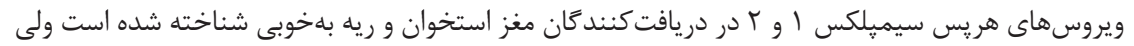

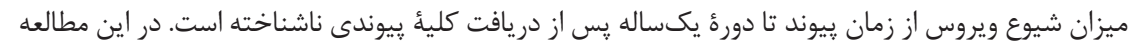

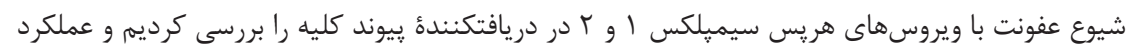

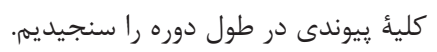

مواد و روشها: اين يزوهش طى يك دوره يكساله روى نمونههاى خون كامل و ادرار هـ هـ دريافتكنندئ

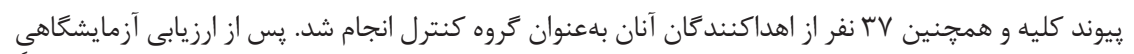

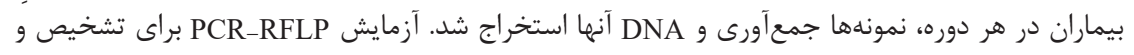

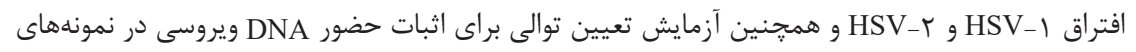
موردمطالعه انجام شد.

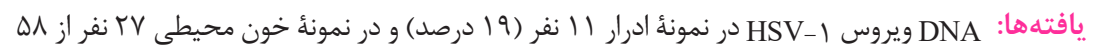

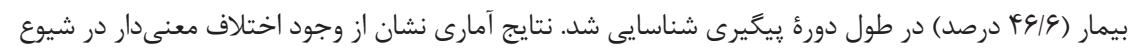
HSV-1

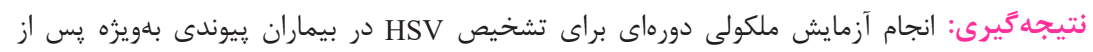

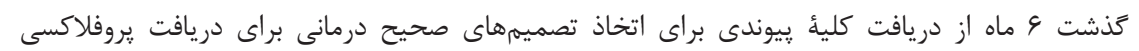
ضدويروسى پيشنهاد مىشود.

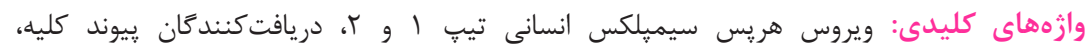
PCR-RFLP
اطلاعات مقاله تاريخجهُ مقاله

دريافت:

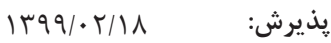

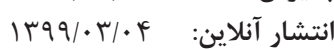

JUR 2019; 3(2):41-48

$$
\text { كد زير را با موبايل خونلود اين مقاله، }
$$

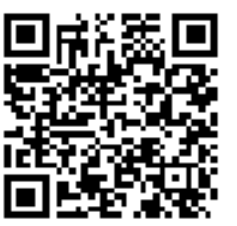

نويسندة مسئول: على فرهادى، استاديار، گروه علومآزمايشَاهى، دانشكده يِيرايزشكى، دانشگاه علوميزشكى شيراز، ايران farhadi_a@sums.ac.ir تلفن : 
به رد يِيوند كمك كند [11]. از طرف ديكر، افزايش تكثير و

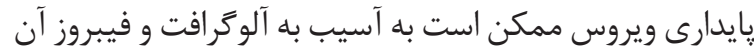

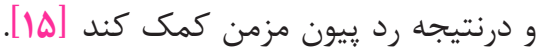

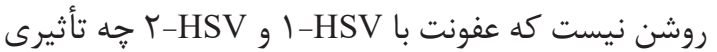
بر نتيجه پِيوند كليه دارد. از اين رو، در اين اين مطالعه شيوع

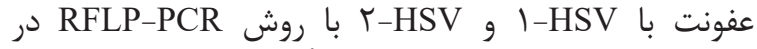
بيماران ي يوند كليه بررسى شد و تأثير عفونتهاى نائ ناشى از

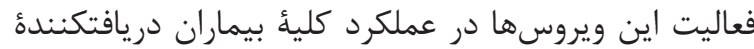
ييوند كليه مورد سنجش قرار ترفت

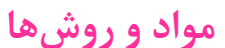

\section{جمعيت موردمطالعه}

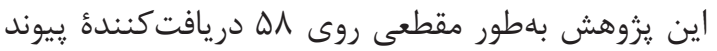

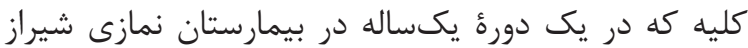

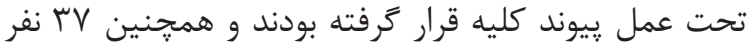

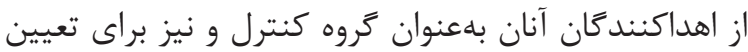

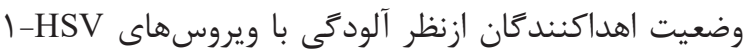

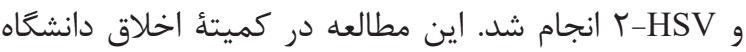

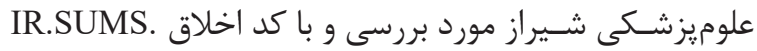

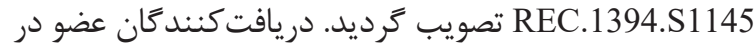

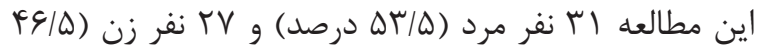

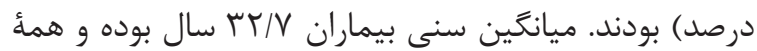

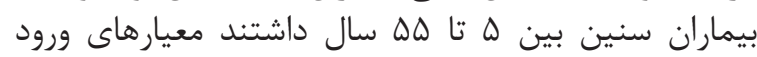

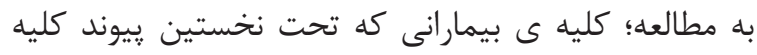

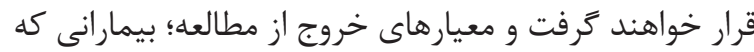

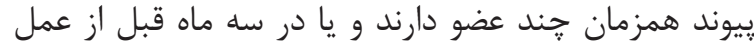

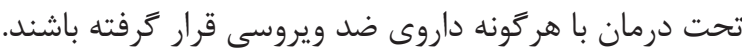

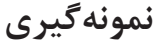

براساس سوابق يزشكى، همؤ بيماران دريافت كننده ئيوند

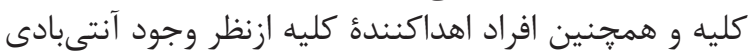

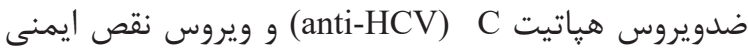
انسان (HIV) و وجود آنتىزن سطحى هياتيت

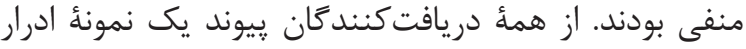

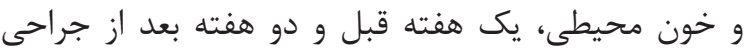

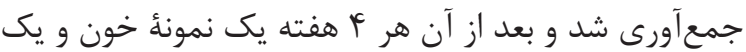

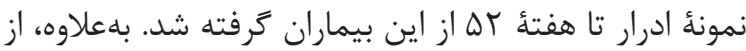

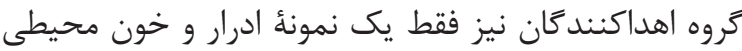

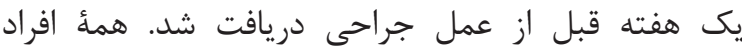

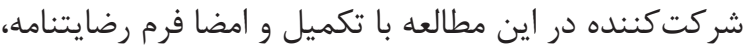

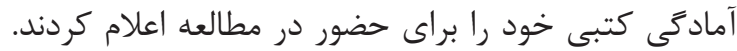

\section{ارزيابى آزمايشعاهى بيماران}

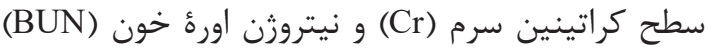

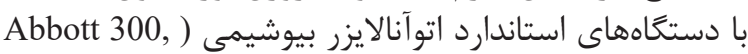
سبيس هر Alcyon. USA

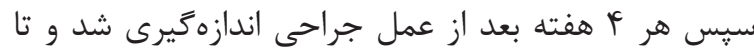

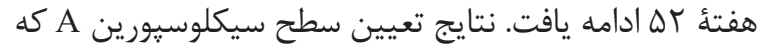

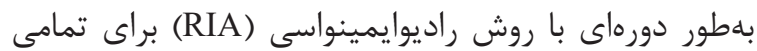
pr
مقال

هريس سيميلكس ا و Y 'دو ويروس از خانواده هريس

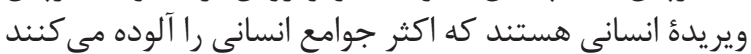

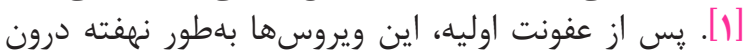

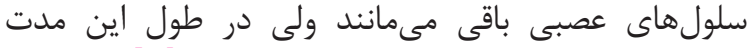

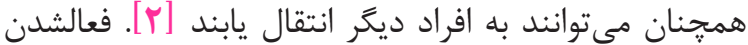

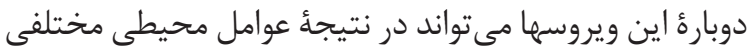

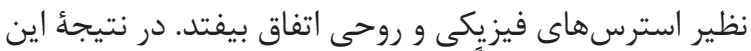

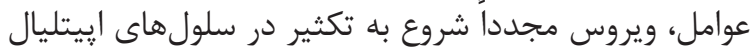

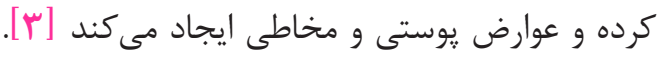

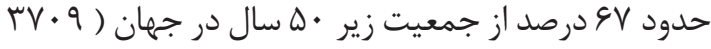

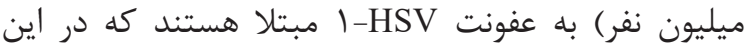

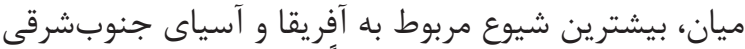

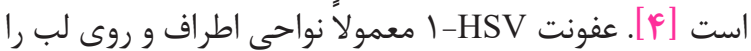

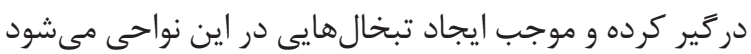

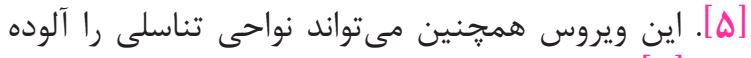

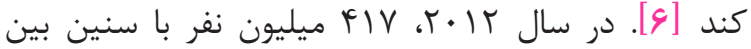

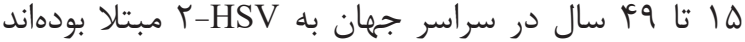

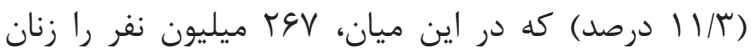

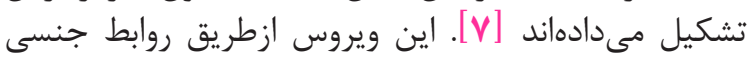

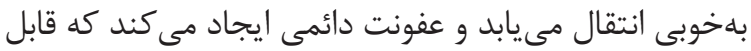

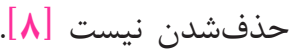
در بيمارانى كه عمل پِيوند عضو انجام دادهاند، بهدليل

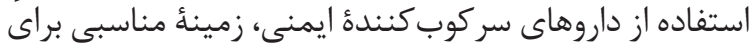

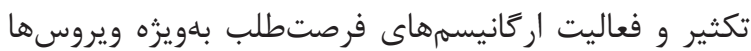

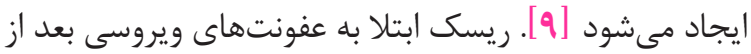

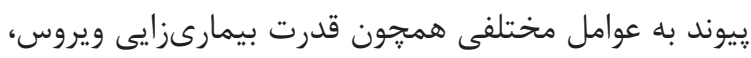

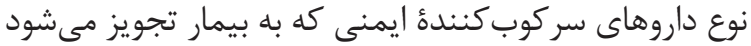

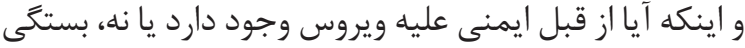

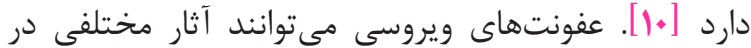

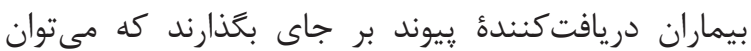

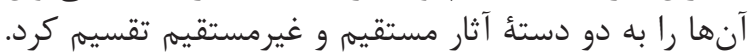

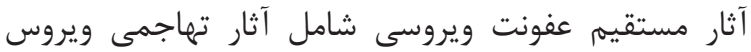

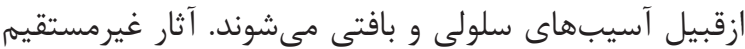

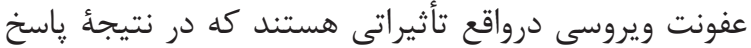

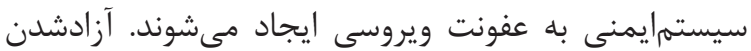

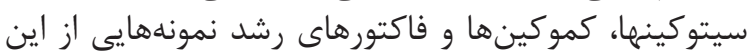

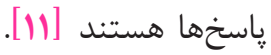
بسيارى از ويروس ها ازجمله ويروس هاى هريس سيميلكس

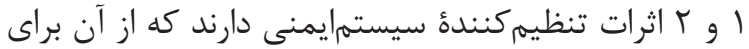

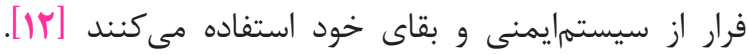

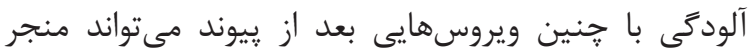

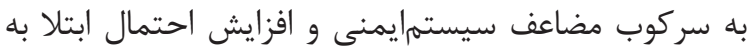

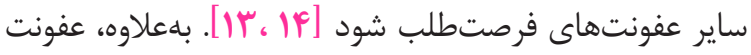

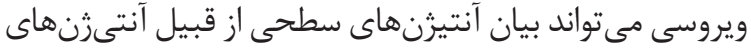

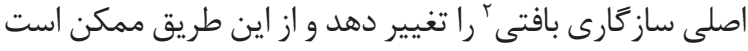

1. Herpes simplex virus $=\mathrm{HSV}$

2. Major Histocompatibility Complex $=\mathrm{MHC}$ 
Thermo با دستخاه نانودراب (شركت DNA هisher Scientific

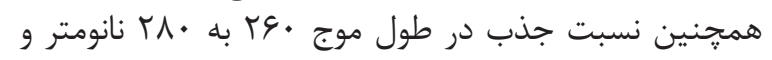

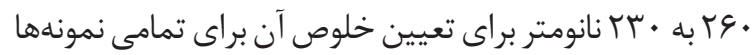

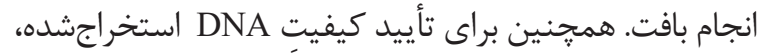

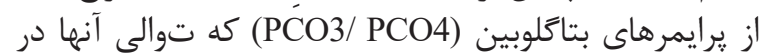

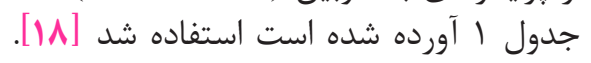

\section{واكنش زنجير هاى يليمراز (PCR')}

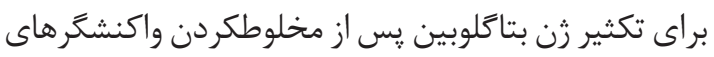

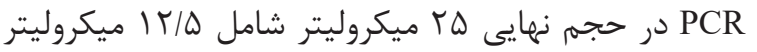

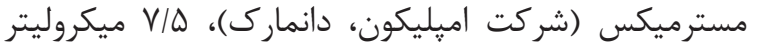

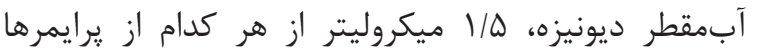

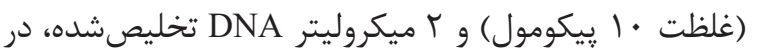

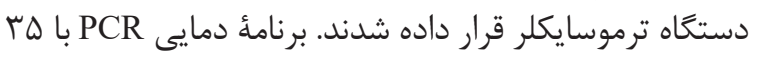

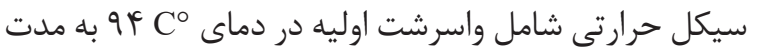
r دقيقه، واسرشت در دماى

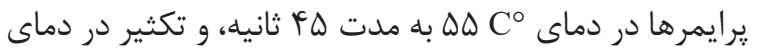

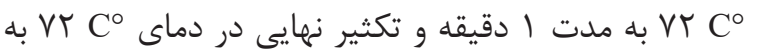
مدت ه دقيقه اعمال شد.

همجنين براى تكثير زن تيميدين كيناز زنوم

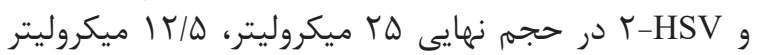

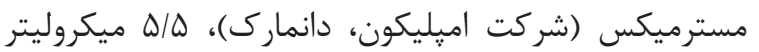

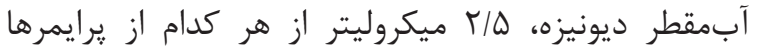

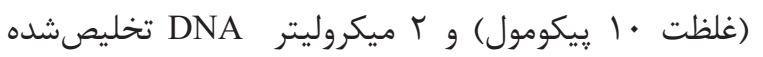

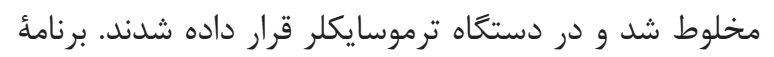

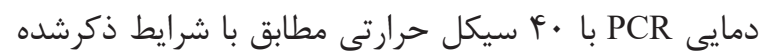

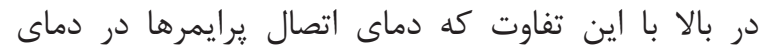

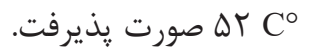

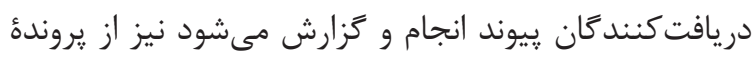

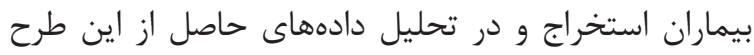

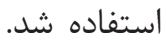

\section{انتخاب و بررسى يرايمرها}

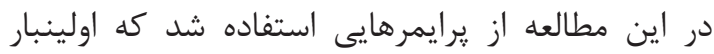
Klapper

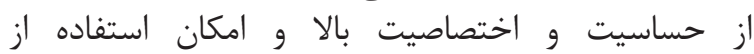

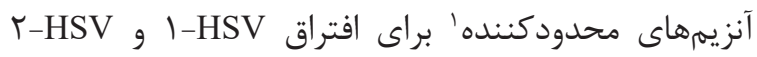

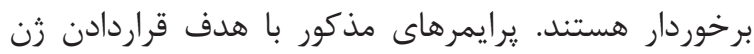

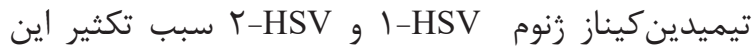

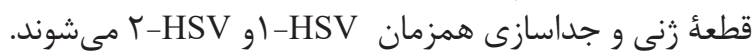

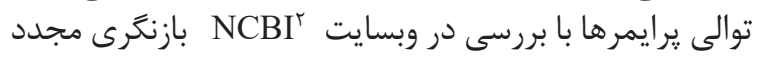

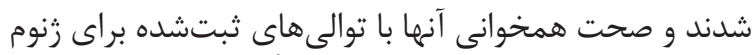

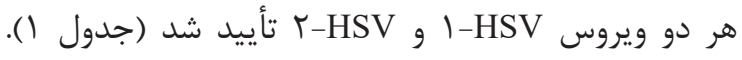

\section{استخراج DNA و بر رسى مقادير كمى و كيفى آن}

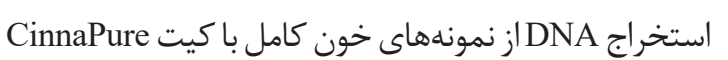

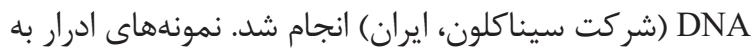

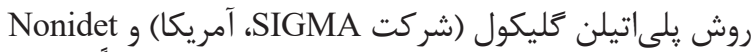

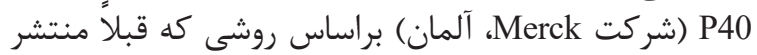

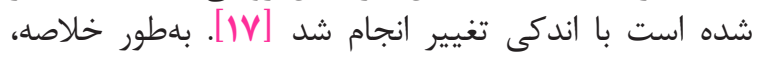

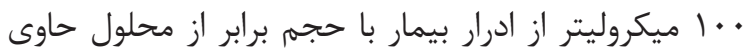

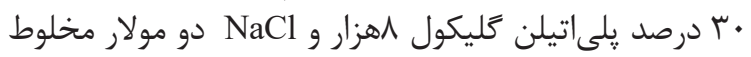

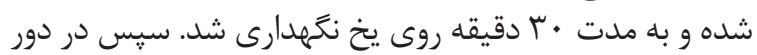

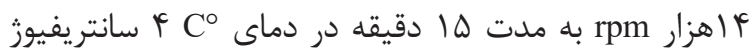

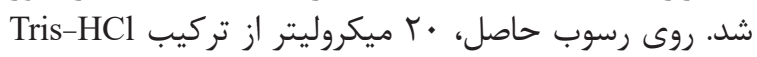

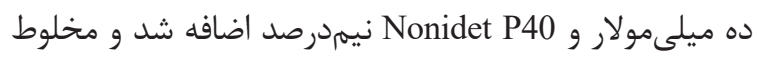

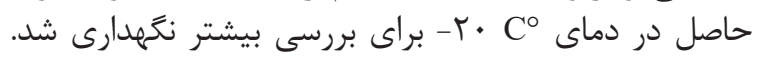

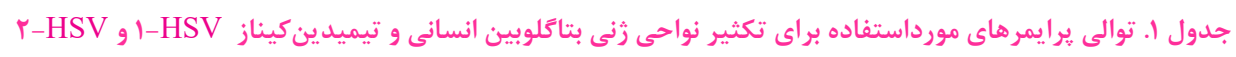

\begin{tabular}{|c|c|c|c|c|}
\hline 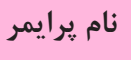 & 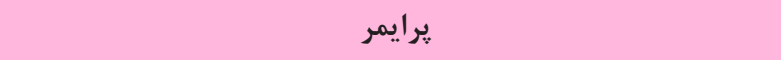 & 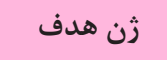 & قطعه (جفت بازى) & منبع \\
\hline $\mathrm{pCO} 3$ & F: 5' ACA CAA CTG TGT TCA CTA GC 3' & \multirow{2}{*}{ بتاگلوبين } & \multirow{2}{*}{11.} & \multirow{2}{*}{11} \\
\hline $\mathrm{pCO} 4$ & R: 5' CAA CTT CAT CCA CGT TCA CC 3' & & & \\
\hline TK1 & F: 5' CGCGCGGTACCTTATGGGCAGCATGA 3' & \multirow{2}{*}{ 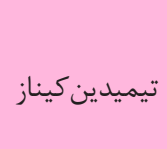 } & \multirow[b]{2}{*}{ ral } & \multirow[b]{2}{*}{19} \\
\hline TK2 & R: 5' CAGGGTAAATAACGTGTCCCCGATATGG 3' & & & \\
\hline
\end{tabular}

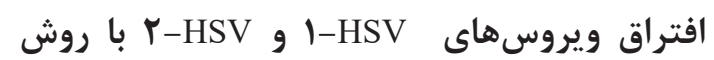
واكنش هضم آنزيمى (افي وماى (RFLP)

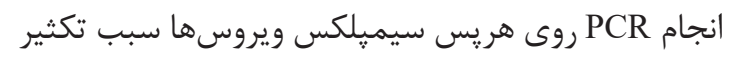

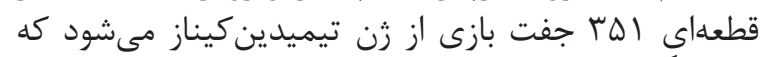

3.Polymerase Chain Reaction

4. Restriction Fragment Length Polymorphism
يس از تهيه و آمادهازى زل آكَارز ها, إ درصد (شركت

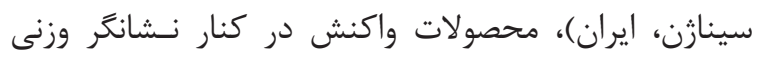

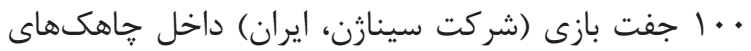

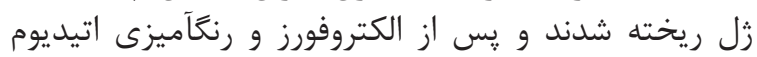

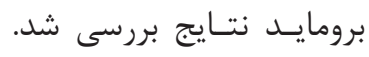

1. Restriction Enzyme

2. http://www. blast.ncbi.nlm.nih.gov/blast/html 
قابلشناسايى بود. به قابل ذكر آنكه DNA ويروس T-HSV

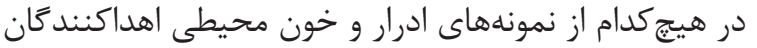

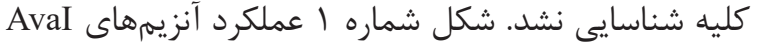

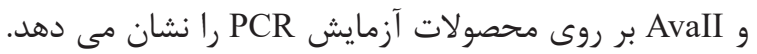
شناسايى جهشهاى شناسايىشدهدرثن تيميدينكيناز

HSV

از ميان VY Y نمونهُ مثبت متعلق به كَروه بيماران، \ بيمار

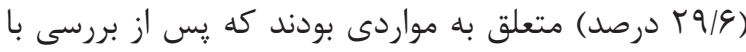

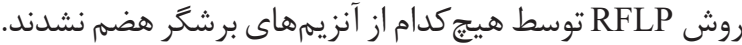

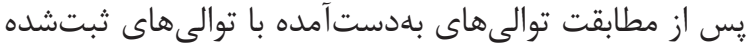

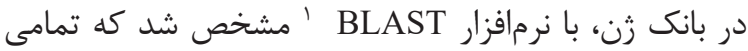

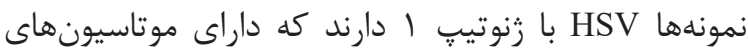

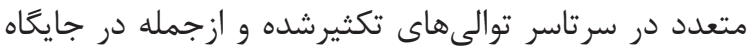

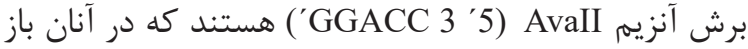

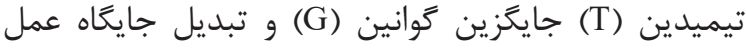

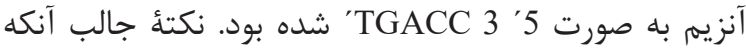

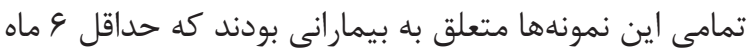

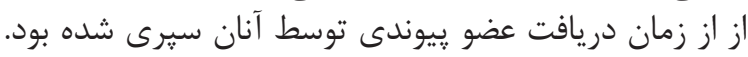

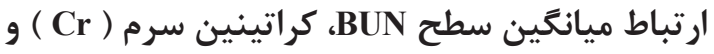

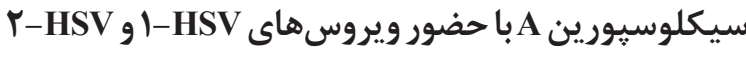

بيماران كيرندة يِيوند براساس مثبت يا منفى بونى

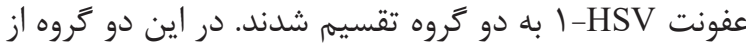

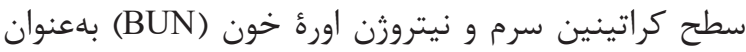

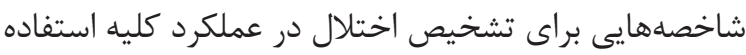
شد. سيس ميانكينهاي سطح BUN

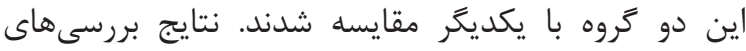

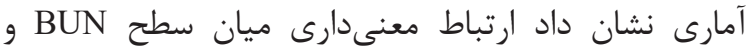

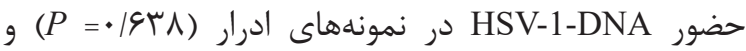
خون محيطى (P) • معنى دارى ميان سطح كراتينين سرم و حضور

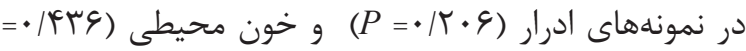

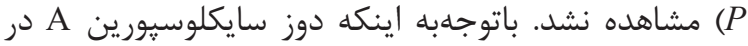

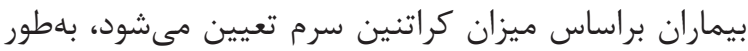

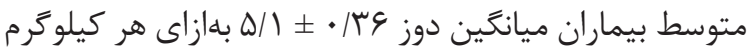

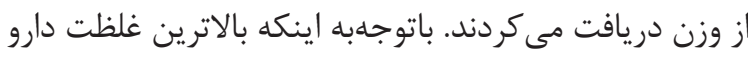

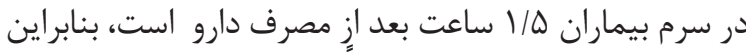

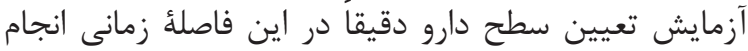

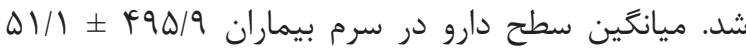

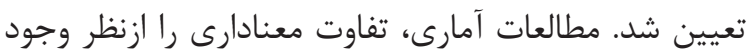

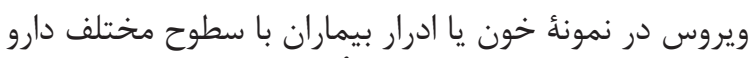

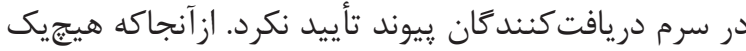

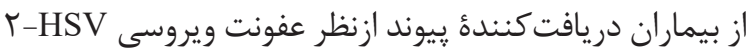

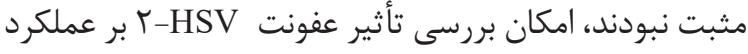

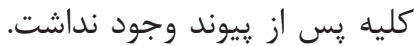

1. http://www. blast.ncbi.nlm.nih.gov/blast/html

is
محصول آن براى HSV-H داراى يك توالى قابلشناسايى

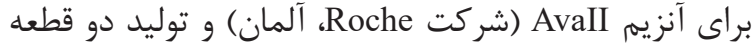

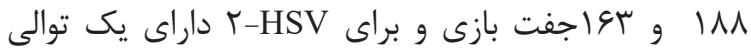

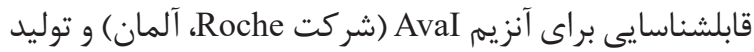

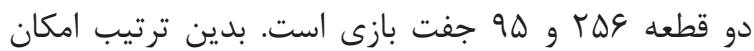

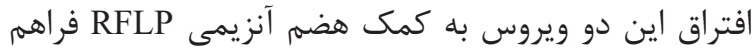

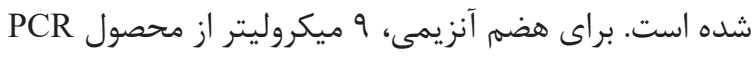

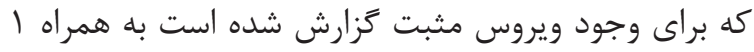

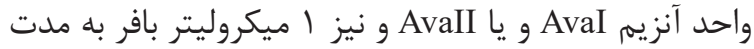

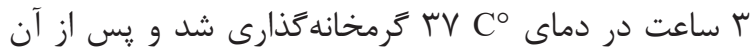

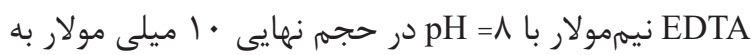

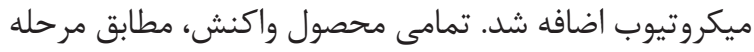

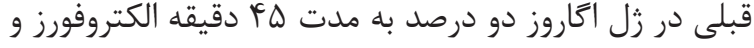

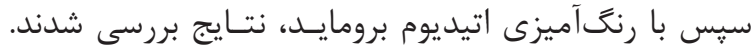

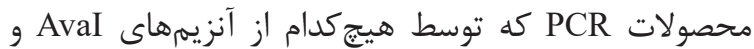

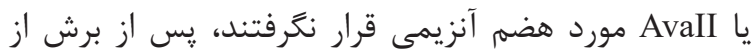

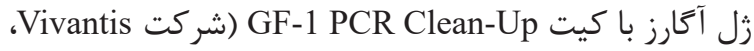

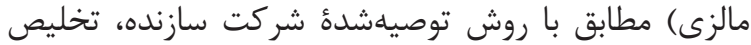

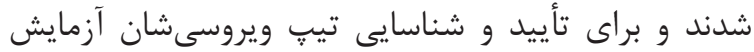

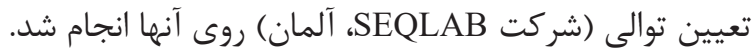

\section{روشهاى تحليل آمارى}

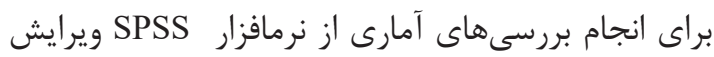

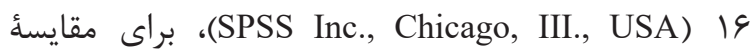

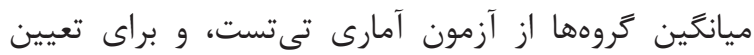

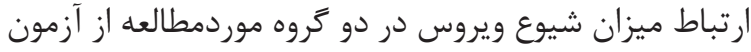

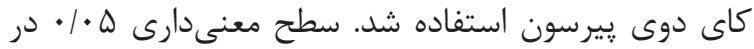

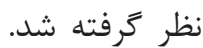

بافنهانها

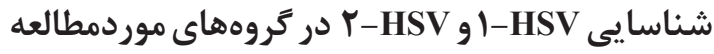

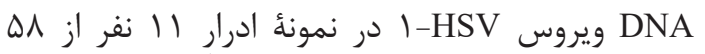

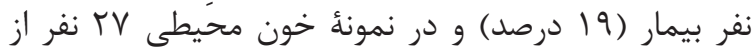

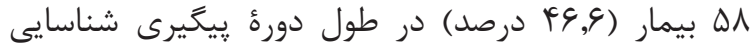

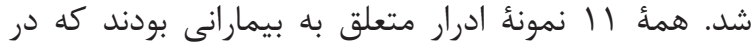

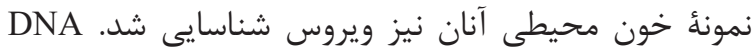

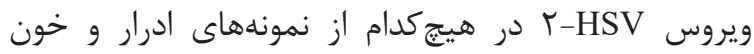

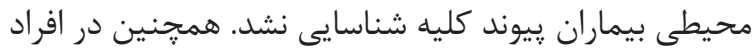

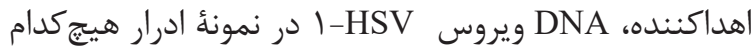

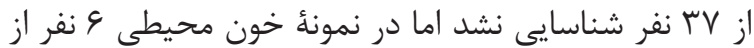

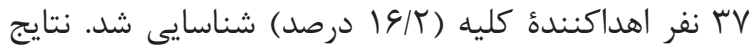

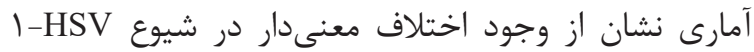

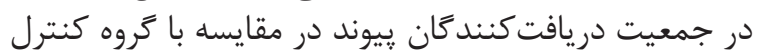

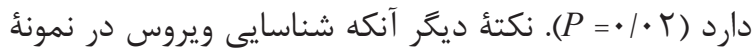

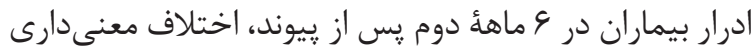

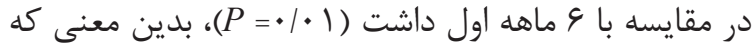
ويروس DNA

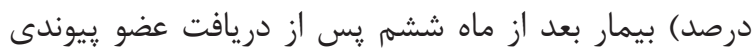




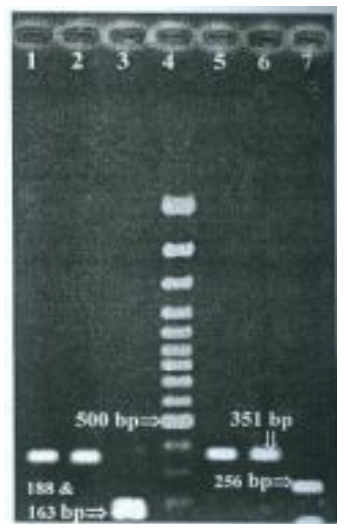

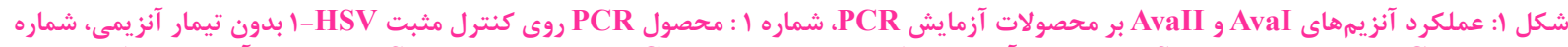

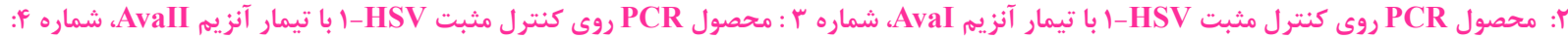

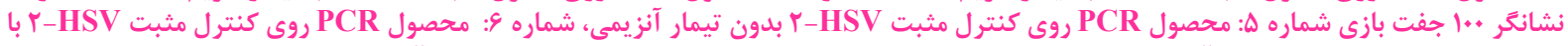

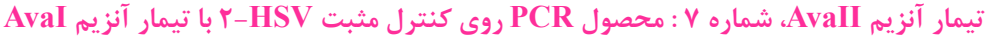

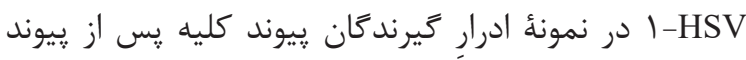

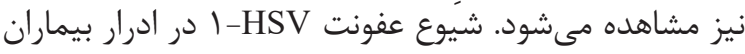

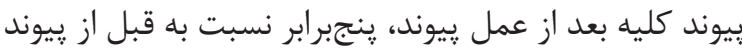
افزايش داشت.

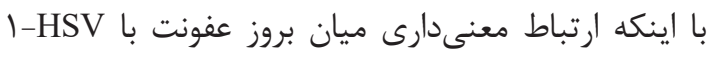

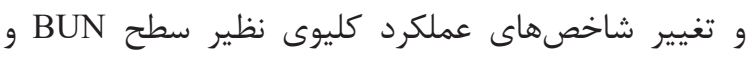

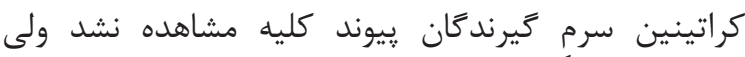

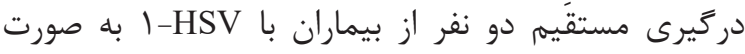

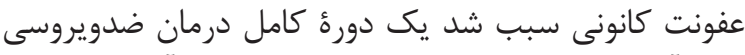

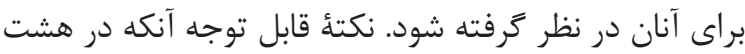

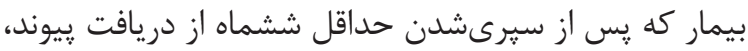

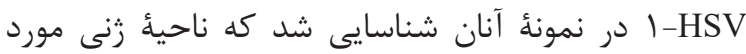

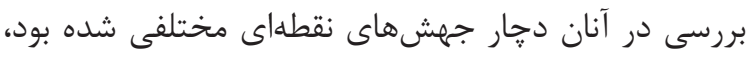

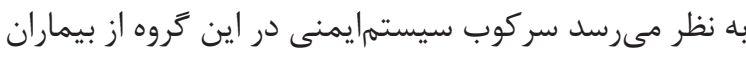

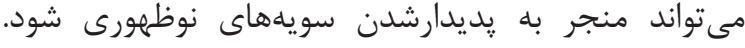

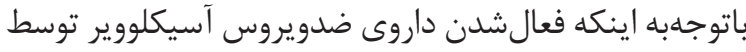

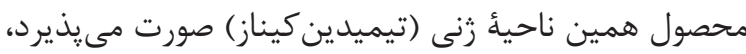

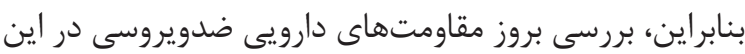

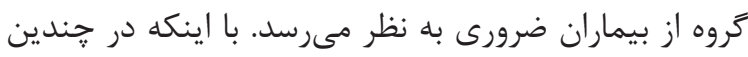

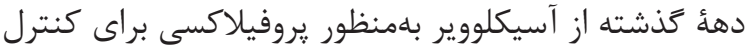

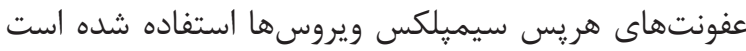

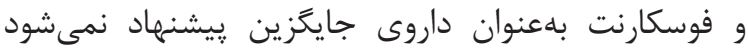

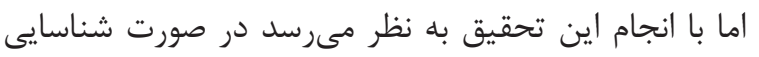

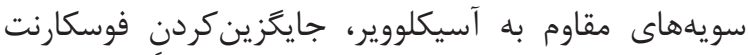

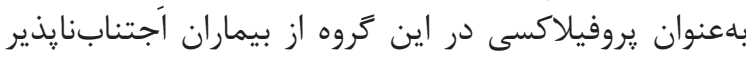

تاكنون به ويروس HSV و بهويزه HSV-1 و و عفونتهاى

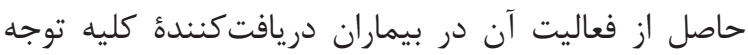

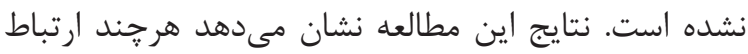

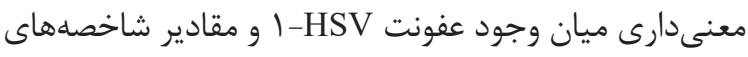

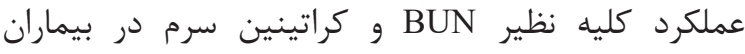

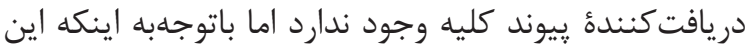

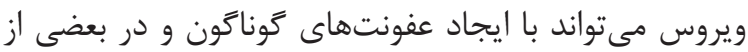

نتيجهَ تَيرى و بحث

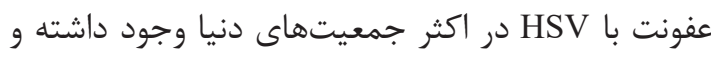

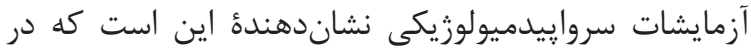

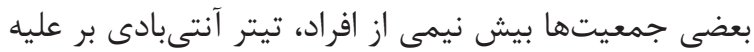

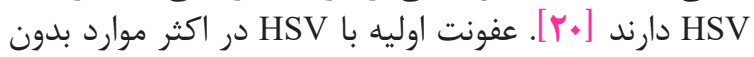

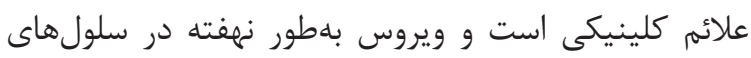

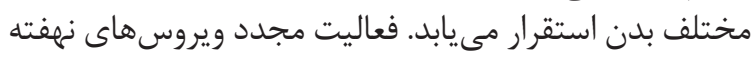

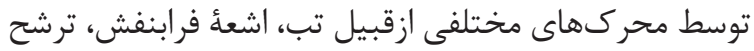

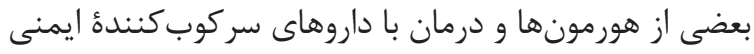

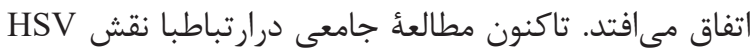

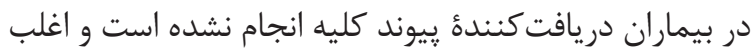

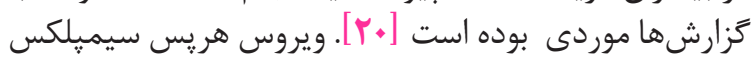

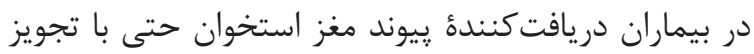

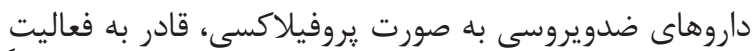

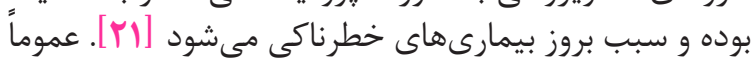

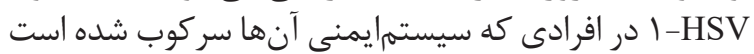

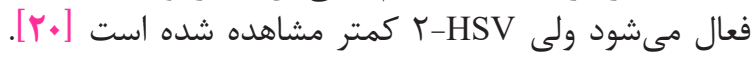

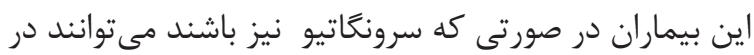

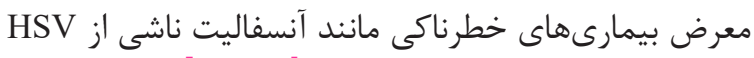

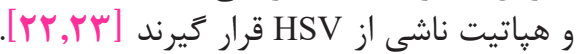

در اين مطالعه، افزايش قابلملاحظهاى در تعداد الداد افرادى

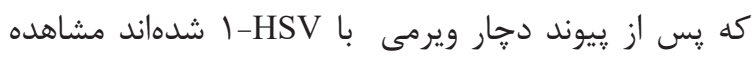

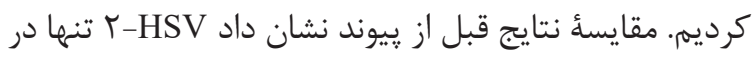

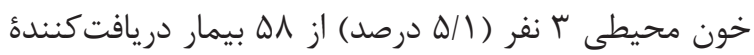

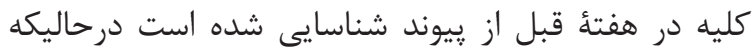

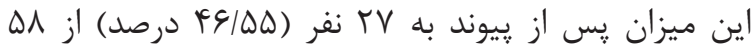

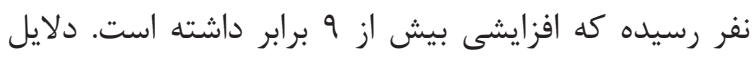

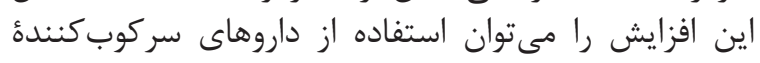

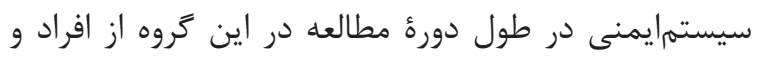

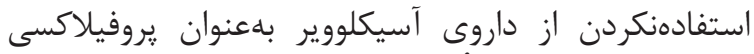

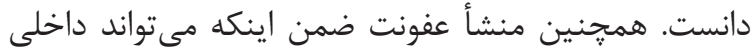

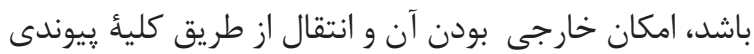

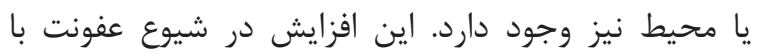




$$
\begin{aligned}
& \text { سياسگزارى } \\
& \text { نويسندكان اين مقاله از رياست محترم سر كار خانم دكتر }
\end{aligned}
$$

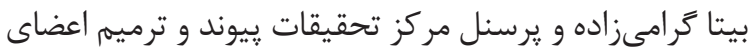

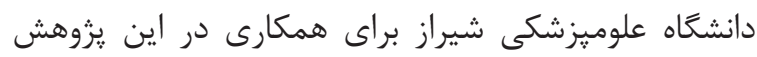

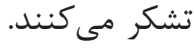

$$
\begin{aligned}
& \text { تعارض در منافع } \\
& \text { بين نويسندكان هيجَّونه تعارضى در منافع وجود ندارد. }
\end{aligned}
$$

\section{References}

1. Akhtar J, Shukla D. Viral entry mechanisms: cellular and viral mediators of herpes simplex virus entry. The FEBS Journal. 2009; 276(24):7228-36. [DOI:10.1111/ j.1742-4658.2009.07402.x] [PMID] [PMCID]

2. Shukla D, Spear PG. Herpesviruses and heparan sulfate: an intimate relationship in aid of viral entry. Journal of Clinical Investigation. 2001; 108(4):503-10. [DOI:10.1172/ JCI200113799] [PMID] [PMCID]

3. Whitley RJ, Roizman B. Herpes simplex virus infections. The lancet. 2001; 357(9267):1513-8. [DOI:10.1016/S01406736(00)04638-9]

4. Looker KJ, Magaret AS, May MT, Turner KM, Vickerman P, Gottlieb SL, et al. Global and regional estimates of prevalent and incident herpes simplex virus type 1 infections in 2012. PloS One. 2015; 10(10): e0140765. [DOI:10.1371/journal. pone. 0140765] [PMID] [PMCID]

5. Arduino PG, Porter S. Oral and perioral herpes simplex virus type 1 (HSV-1) infection: review of its management. Oral Diseases. 2006; 12(3):254-7 [DOI:10.1111/ j.1601-0825.2006.01202.x] [PMID]

6. Lafferty WE, Downey L, Celum C, Wald A. Herpes simplex virus type 1 as a cause of genital herpes: impact on surveillance and prevention. Journal of Infection. 2000; 181(4):1454-7. [DOI:10.1086/315395] [PMID]

7. Looker KJ, Magaret AS, Turner KM, Vickerman P, Gottlieb SL, Newman LM. Global
موارد با ايجاد عفونتهاى سيستميك خطرناى، فارغ از تأثير

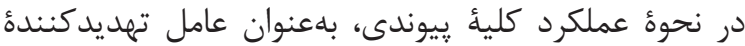

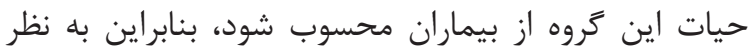

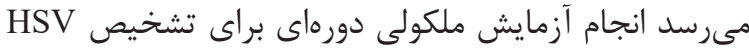

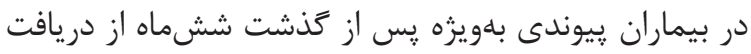

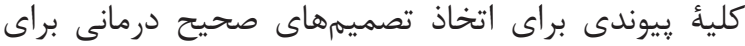

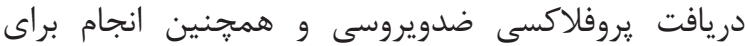

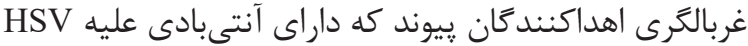

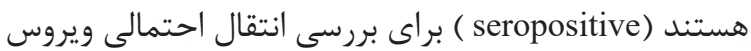
از طريق عضو يِوندى ضرورى است.

estimates of prevalent and incident herpes simplex virus type 2 infections in 2012. PloS One. 2015; 10(1): e114989. [DOI:10.1371/ journal.pone.0114989] [PMID] [PMCID]

8. Johnston C, Corey L. Current concepts for genital herpes simplex virus infection: diagnostics and pathogenesis of genital tract shedding. Clinical Microbiology Reviews. 2016; 29(1):149-61. [DOI:10.1128/ CMR.00043-15] [PMID] [PMCID]

9. Wilck M, Zuckerman R, Practice AIDCo. Herpes simplex virus in solid organ transplantation. American Journal of Transplantation. 2013; 13(s4):121-7. [DOI:10.1111/ ajt.12105] [PMID]

10. Bernabeu-Wittel M, Naranjo M, Cisneros J, Canas E, Gentil M, Algarra G, et al. Infections in renal transplant recipients receiving mycophenolate versus azathioprine-based immunosuppression. European Journal of Clinical Microbiology \& Infectious Diseases. 2002; 21(3):173-80. [DOI:10.1007/ s10096-001-0684-y] [PMID]

11. Kotton CN, Fishman JA. Viral infection in the renal transplant recipient. Clinical Journal of the American Society of Nephrology. 2005; 16(6):1758-74. [DOI:10.1681/ ASN.2004121113] [PMID]

12. Sarikonda G, von Herrath MG. Immunosuppressive mechanisms during viral infectious diseases. Suppression and Regulation of Immune Responses: Springer; 2010. p. 431-47. [DOI:10.1007/978-1-60761-8690 27] [PMID] [PMCID]

13. Ljungman P. $\beta$-Herpesvirus challenges in the transplant recipient. Journal of Infec-

kV 


$$
\text { على فرهادى و همكاران اعفونت ويروسهاى هريس سيميلكس تيب ا و كوميزان عملكرد كليوى آنان }
$$

tion. 2002; 186(Supplement-1): S99-S109. [DOI:10.1086/342962] [PMID]

14. Boeckh M, Nichols WG. Immunosuppressive effects of beta-herpesviruses. Herpes: The Journal of the IHMF. 2003; 10(1):12-6.

15. Babel N, Schwarzmann F, Prang N, Jaeger M, Wolf H, Kern F, et al. Association between epstein-barr virus infection and late acute transplant rejection in long-term transplant patients. Transplantation. 2001; 72(4):736-9. [DOI:10.1097/00007890200108270-00031] [PMID]

16. Klapper PE, Cleator GM, Dennett C, Lewis AG. Diagnosis of herpes encephalitis via Southern blotting of cerebrospinal fluid DNA amplified by polymerase chain reaction. Journal of Medical Virology. 1990; 32(4):261-4. [DOI:10.1002/ jmv.1890320413] [PMID]

17. Behzadbehbahani A, Klapper PE, Vallely PJ, Cleator GM. Detection of BK virus in urine by polymerase chain reaction: a comparison of DNA extraction methods. Journal of Virological Methods. 1997; 67(2):161-6. [DOI:10.1016/S0166-0934(97)00101-8]

18. Saiki RK, Bugawan TL, Horn GT, Mullis $\mathrm{KB}$, Erlich HA. Analysis of enzymatically amplified $\beta$-globin and HLA-DQ $\alpha$ DNA with allele-specific oligonucleotide probes. Nature. 1986; 324(6093):163. [DOI:10.1038/324163a0] [PMID]
19. Bradley H, Markowitz LE, Gibson T, McQuillan GM. Seroprevalence of herpes simplex virus types 1 and 2-United States, 1999-2010. Journal of Infection. 2013; 209(3):325-33. [DOI:10.1093/infdis/ jit458] [PMID]

20. Gomez E, Melon S, De Ona M, Alvarez R, Laures A, Alvarez-Grande J. Disseminated herpes simplex virus infection in a renal transplant patient as possible cause of repeated urinary extravasations. Nephron. 1999; 82(1):59-64. [DOI:10.1159/000045368] [PMID]

21. Fillet AM. Prophylaxis of herpesvirus infections in immunocompetent and immunocompromised older patients. Drugs \& Aging. 2002; 19(5):343-54. [DOI:10.2165/00002512-20021905000003] [PMID]

22. Kusne S, Schwartz M, Breinig MK, Dummer JS, Lee RE, Selby R, et al. Herpes simplex virus hepatitis after solid organ transplantation in adults. Journal of Infection. 1991; 163(5):1001-7. [DOI:10.1093/ infdis/163.5.1001] [PMID] [PMCID]

23. Amenabar J, Duran M, Montejo M, Lampreabe I. Herpes simplex virus encephalitis in a renal transplant patient. Nefrologia: publicacion oficial de la Sociedad Espanola Nefrologia. 2006; 26(2):270-3. 